\title{
Spebrutinib (CC-292) Affects Markers of B Cell Activation, Chemotaxis, and Osteoclasts in Patients with Rheumatoid Arthritis: Results from a Mechanistic Study
}

\author{
Peter H. Schafer · Alan J. Kivitz · Jianglin Ma · Shimon Korish • \\ Donna Sutherland · Li Li · Ada Azaryan · Jolanta Kosek • Mary Adams • \\ Lori Capone · Eun Mi Hur · Douglas R. Hough · Garth E. Ringheim
}

Received: July 16, 2019 / Published online: November 13, 2019

(C) The Author(s) 2019

\section{ABSTRACT}

Introduction: Spebrutinib (CC-292) is an orally administered, covalent, small-molecule inhibitor of Bruton's tyrosine kinase (BTK), part of the B-cell and Fc receptor signaling pathways. This study evaluated spebrutinib pharmacology and mechanism of action over a 4 -week treatment period in patients with active rheumatoid arthritis (RA).

Methods: Primary human B cells, T cells, natural killer cells, macrophages, dendritic cells, basophils, and osteoclasts were treated with spebrutinib in vitro. Clinical pharmacodynamics were studied in 47 patients with active RA on

Enhanced Digital Features To view enhanced digital features for this article go to: https://doi.org/10.6084/ m9.figshare.10049777.

Electronic Supplementary Material The online version of this article (https://doi.org/10.1007/s40744019-00182-7) contains supplementary material, which is available to authorized users.

P. H. Schafer $(\bowtie)$

Celgene Corporation, 86 Morris Avenue, L Building, Summit, NJ, USA

e-mail: pschafer@celgene.com

A. J. Kivitz

Altoona Center for Clinical Research, Duncansville, PA, USA

J. Ma · S. Korish · D. Sutherland · L. Li · A. Azaryan

· J. Kosek · M. Adams - L. Capone - E. M. Hur .

D. R. Hough · G. E. Ringheim

Celgene Corporation, Summit, NJ, USA background methotrexate therapy randomized to oral spebrutinib $375 \mathrm{mg}$ /day or placebo.

Results: In vitro, spebrutinib inhibited B-cell proliferation more potently than T-cell proliferation and reduced both lymphoid and myeloid cytokine production and degranulation, as well as osteoclastogenesis. Clinical efficacy trended higher in spebrutinib-treated RA patients, with $41.7 \%$ (10/ 24) achieving $\geq 20 \%$ improvement in ACR response criteria (ACR20) versus $21.7 \%(5 / 23)$ of placebo patients at week $4(P=0.25)$. Treatmentemergent adverse events were comparable between treatment groups. In spebrutinib-treated patients, median BTK occupancy in peripheral blood was $83 \%$, and significant increases in total $\mathrm{CD}^{+} 9^{+}$and mature-naive $\mathrm{CD}_{27}^{-} \mathrm{CD}^{-} 8^{-} \mathrm{IgD}^{+} \mathrm{B}$ cells and decreases in transitional $\mathrm{CD}_{2} 7^{-} \mathrm{CD} 38^{+} \mathrm{B}$ cells were observed. Spebrutinib significantly reduced serum chemokines chemokine ligand 13 (CXCL13), macrophage inflammatory protein-1 $\beta$ (MIP-1 $\beta$ ), and the bone resorption biomarker carboxy-terminal collagen cross-linking telopeptide (CTX-I) $(P<0.05)$. Clinical response to spebrutinib was associated with lower increases in $\mathrm{CD} 19^{+} \mathrm{B}$ cells and greater decreases in CXCL13 and MIP-1 $\beta$ from baseline to week 4 . High CD19 ${ }^{+}$B cells and low CTX-I at baseline were associated with better spebrutinib clinical response.

Conclusions: Spebrutinib inhibited various leukocyte responses in vitro, including those of B cells and osteoclasts. In this small study in RA patients, spebrutinib was well tolerated, showed a downward trend for symptoms, significantly 
modulated B-cell populations, and reduced markers of chemotaxis and osteoclast activity.

Trial Registration: NCT01975610.

Keywords: Background methotrexate therapy; Bruton's tyrosine kinase inhibitor; CC-292; Rheumatoid arthritis; Spebrutinib

\section{Key Summary Points}

Why carry out this study?

Bruton's tyrosine kinase (BTK) has been proposed as a therapeutic target for the treatment of autoimmune and inflammatory diseases such as rheumatoid arthritis (RA), based on its role in B-cell receptor and $\mathrm{Fc}$ receptor signaling.

Spebrutinib (CC-292) is an oral small molecule that inhibits BTK activity by irreversible covalent binding with high affinity to the BTK adenosine triphosphate binding site in $\mathrm{B}$ and myeloid cells.

This phase 2 a clinical study was conducted to evaluate spebrutinib efficacy and safety in female patients with active RA who were receiving a stable methotrexate dose as background therapy. The study also evaluated spebrutinib pharmacodynamic effects on circulating levels of BTK, B-cell subsets, and signaling factors essential to BTK activity.

\section{What was learned from the study?}

Spebrutinib treatment led to statistically significant changes versus placebo across several biomarkers of anti-inflammatory activity, confirming its mechanism of action and potential therapeutic biological effects in RA

The pharmacodynamics of BTK inhibition in RA patients demonstrated a significant impact on B-cell differentiation, chemokine expression, and osteoclast activity that potentially provides a set of biomarkers useful in developing BTK inhibitors for the treatment of RA.

\section{INTRODUCTION}

Rheumatoid arthritis (RA) is a chronic, systemic autoimmune disorder initiated by dysregulation of $\mathrm{T}$ and $\mathrm{B}$ lymphocytes. Its pathology includes expansion of B cells, which leads to formation of autoantibodies [1]. Bruton's tyrosine kinase (BTK) is found in B cells but not in T cells or natural killer (NK) cells within the lymphoid lineage. BTK is required for B-cell activation by engagement of the B-cell antigen receptor (BCR) and is involved in B-cell differentiation, chemotaxis, and trafficking $[2,3]$. Inhibition or lack of BTK is marked by increased numbers of B cells in circulating blood and reduced B-cell chemotaxis and accumulation in secondary lymphoid organs $[1,4]$. Inhibition of BTK activity is associated with reduced lymphadenopathy in patients with chronic lymphocytic leukemia [5]. BTK is also expressed in myeloid cells, where it is involved in activating Fc-gamma and Fc-epsilon receptors (Fc $\gamma \mathrm{R}$ and FceR) pathways in macrophages, neutrophils, and monocytes [1]. Together, these properties suggest BTK is an attractive target for B-cell inhibition in RA [1].

Spebrutinib (CC-292) is an oral small molecule which inhibits BTK activity by irreversible covalent binding with high affinity to the BTK adenosine triphosphate binding site in $\mathrm{B}$ and myeloid cells. By providing rapid, complete, and prolonged inhibition of BTK activity, spebrutinib may be therapeutically active in RA and other B-cell-mediated autoimmune disorders. Preclinical studies have shown that administration of spebrutinib led to blockade of BCR-dependent B-cell activation, inhibition of Fc $\gamma$ R-induced inflammatory cytokine production in myeloid cells, and a reduction in osteoclastogenesis [6-8]. Spebrutinib has demonstrated BCR selectivity, potency, and efficacy in a collagen-induced arthritis model in mice [7]. In a small, first-in-human safety and pharmacokinetic/pharmacodynamics analysis of healthy volunteers, spebrutinib led to nearcomplete BTK occupancy 8-24 h after administration [7].

This phase 2a multicenter, US-based clinical study was conducted to evaluate spebrutinib 
efficacy and safety in female patients with active RA who were receiving a stable methotrexate dose as background therapy. The study also evaluated spebrutinib pharmacodynamic effects on circulating levels of BTK, B-cell subsets, and signaling factors essential to BTK activity.

\section{METHODS}

\section{Preclinical Pharmacology}

Human primary B cells $\left(\mathrm{CD} 19^{+}\right)$were isolated from leukopacks from healthy donors obtained from Biological Specialty (Colmar, PA, USA). Peripheral blood mononuclear cells (PBMC) were first isolated by density gradient centrifugation using Ficoll (GE Healthcare, Chicago, IL, USA) followed by the EasySep Human Naive B Cell Enrichment Kit (Stemcell Technologies, Vancouver, BC, Canada) according to manufacturing protocol. $\mathrm{CD}^{+}$and $\mathrm{CD}^{+} \mathrm{T}$ cells were isolated from PBMC using EasySep Human $\mathrm{CD}^{+}$and $\mathrm{CD}^{+}{ }^{+} \mathrm{T}$ Cell Enrichment Kits. NK cells were purified from PBMC using the EasySep Human NK Cell Enrichment Kit.

\section{Immunoblot Analysis of Phospho- phospholipase $C \gamma$}

Quantitation of phospho-phospholipase $\mathrm{C} \gamma$ was by Western-blot analysis of $\alpha$-IgM-stimulated B cells, as described previously [7].

\section{$B$ - and T-Cell Proliferation}

B cells $\left(0.2 \times 10^{6}\right.$ cells in $\left.200 \mu \mathrm{l}\right)$ or $\mathrm{T}$ cells $\left(0.2 \times 10^{6}\right.$ cells in $\left.100 \mu \mathrm{l}\right)$ were incubated for $1 \mathrm{~h}$ with spebrutinib $(0.0001-100 \mu \mathrm{M})$ followed by stimulation of B cells with $\alpha$-IgM $(10 \mu \mathrm{g} / \mathrm{ml})$ and CpG $(10 \mu \mathrm{g} / \mathrm{ml})$, or T cells with $\alpha$-CD3 $(1 \mu \mathrm{g} / \mathrm{ml})$, and $\alpha$-CD28 $(3 \mu \mathrm{g} / \mathrm{ml})$ for 3 days. ${ }^{3} \mathrm{H}$-thymidine $(1 \mu \mathrm{Ci} /$ well) was added the last $24 \mathrm{~h}$, harvested, and measured for incorporation.

\section{T-Cell Interferon- $\gamma$ Secretion}

Human primary $\mathrm{T}$ cells $\left(\mathrm{CD}^{+}\right)$were isolated from leukopacks from healthy donors using the EasySep Human T Cell Enrichment Kit (Stemcell
Technologies, Vancouver, BC, Canada) according to manufacturing protocol. $\mathrm{T}$ cells were incubated for $1 \mathrm{~h}$ with spebrutinib followed by stimulation with soluble $\alpha$-CD3 $(3 \mu \mathrm{g} / \mathrm{ml})$ and $\alpha$ CD28 $(1 \mu \mathrm{g} / \mathrm{ml})$ for $48 \mathrm{~h}$. Supernatants were analyzed in duplicate for interferon- $\gamma$ cytokine production in a magnetic multiplex bead format using the MagPix instrument (Millipore, Billerica, MA, USA). Data analysis was performed using Milliplex Analyst Software (Millipore).

\section{NK- and $\mathrm{CDB}^{+}$T-Cell Degranulation}

$\mathrm{NK}$ and $\mathrm{CD}^{+}$cells were incubated for $1 \mathrm{~h}$ with spebrutinib followed by addition of antiCD107a antibody for $1 \mathrm{~h}$, then monensin, Brefeldin A, and stimulation with $5 \mu \mathrm{g} / \mathrm{ml}$ of antiCD3 and $1 \mu \mathrm{g} / \mathrm{ml}$ of anti-CD28 (for $\mathrm{CD}^{+} \mathrm{T}$ cells) and $0.1 \times 10^{6} \mathrm{~K} 562$ cells (for NK cells) for $5 \mathrm{~h}$ to initiate degranulation. Cell surface marker CD107a was measured by flow cytometry.

\section{Plasmablast Differentiation and IgG and IL-6 Secretion}

Plasmablast generation and IgG production were measured by preincubation of B cells for $1 \mathrm{~h}$ with spebrutinib followed by addition of anti-IgM, CD40 , interleukin (IL)-21 and IL-2 for 5 days, as described previously [9]. On day 5, IgG was measured by enzyme-linked immunosorbent assay (ELISA) and plasmablast levels by flow cytometry of CD20-CD38 ${ }^{+}$gated cells. Supernatants were measured on day 2 for IL- 6 by ELISA.

\section{B-Cell Activation}

$\mathrm{CD} 19^{+} \mathrm{B}$ cells were incubated $1 \mathrm{~h}$ with spebrutinib followed by stimulation of B cells with $\alpha$ $\operatorname{IgM}(10 \mu \mathrm{g} / \mathrm{ml})$ and CpG $(10 \mu \mathrm{g} / \mathrm{ml})$ for $24 \mathrm{~h}$ and measurement of CD86, CD40, CD54, and CD69 by flow cytometry.

Fc $\gamma$ R-Stimulated Macrophage TNF- $\alpha$ Secretion Human primary monocytes were isolated from PBMC using the EasySep Negative Selection Human Monocyte Isolation Kit (Stemcell Technologies) and cultured in Petri dishes in the presence of $5-\mu \mathrm{g} / \mathrm{ml}$ granulocyte-macrophage colony-stimulating factor (GM-CSF) in medium 
(RPMI1640, 10\% fetal bovine serum, 2-mM Lglutamine, 25-mM HEPES, $100 \mathrm{U} / \mathrm{ml}$ each of penicillin/streptomycin). Cells were given $5-\mathrm{ml}$ additional medium containing $5-\mu \mathrm{g} / \mathrm{ml} \mathrm{GM-CSF}$ twice per week for $\approx 2$ weeks for differentiation to macrophages.

Human primary monocytes or macrophages differentiated from monocytes in vitro were resuspended in complete culture medium counted and diluted to $1 \times 10^{6} / \mathrm{ml} ; 50 \mu \mathrm{l}$ of cells in medium was seeded into 96-well polypropylene culture plates and $25 \mu \mathrm{l}$ of culture medium was added to the wells, then spebrutinib $25 \mu \mathrm{l}$ (four times the final concentration) was added and incubated for $30 \mathrm{~min}$. For IgG-coated plates preparation, 96-well polystyrene plates were coated with human IgG $(200 \mu \mathrm{l}$ of $100 \mu \mathrm{g} / \mathrm{ml}$ in PBS) for $2 \mathrm{~h}$ before washing three times with PBS. Cell plates were then transferred to IgGcoated plates and incubated for $24 \mathrm{~h}$ before removing culture medium for measuring tumor necrosis factor (TNF)- $\alpha$ by ELISA (Quantikine ELISA Kit; R\&D Systems, Minneapolis, MN, USA).

\section{Cell Viability}

Cell viability was measured using Promega's CellTiter 96 Aqueous One Solution Cell Proliferation Assay (MTS). In all, $75 \mu \mathrm{l}$ of medium was removed for ELISAs and $75 \mu$ lof fresh, warmed medium placed back into the wells followed by $20 \mu \mathrm{l}$ of the kit solution. Cells were placed back into the tissue culture incubator for $\approx 1 \mathrm{~h}$ or until an OD490 > 1.0 was reached whereon the whole plate was quantified by reading the OD490 on a spectrophotometer plate reader.

\section{CpG Stimulation of Toll-Like Receptor 9-Activated Myeloid-Derived Dendritic Cells}

Monocytes were purified by the Human CD14 Selection Kit and differentiated into myeloidderived immature dendritic cells by incubation with IL-4 (35 ng/ml) and GM-CSF (50 ng/ml) for 5 days. Cells were harvested and plated at $1 \times 10^{4} / 400 \mu \mathrm{l}$ in deep-well plates. Cells were incubated for $1 \mathrm{~h}$ with spebrutinib followed by addition of CpG $(5 \mu \mathrm{M})$ or lipopolysaccharide $(1 \mu \mathrm{g} / \mathrm{ml})$ and incubated for $24 \mathrm{~h}$. Cells were then harvested and CD86 measured by flow cytometry.

\section{Basophil Degranulation}

Heparinized whole blood from healthy donors was pre-incubated with spebrutinib for $1 \mathrm{~h}$ at $37^{\circ} \mathrm{C}$ followed by stimulation with anti-IgE $0.312 \mu \mathrm{g} / \mathrm{ml}$ for $20 \mathrm{~min}$. Cells were then put on ice to stop degranulation and stained with $\alpha$-IgE-PE and $\alpha$-CD63 antibodyFITC for $20 \mathrm{~min}$. Whole blood was lysed, fixed, and washed. Cells were re-suspended in buffer and analyzed by flow cytometry within $2 \mathrm{~h}$. Data were analyzed and calculated using FlowJo software. Raw data were normalized to positive control (dimethyl sulfoxide only) and half maximal inhibitory concentration $\left(\mathrm{IC}_{50}\right)$ was calculated with GraphPad Prism. All treatment groups were compared with dimethyl sulfoxide by one-way analysis of variance followed by Dunnett's multiple comparison post-test.

\section{Osteoclast Differentiation}

Bone marrow mononuclear cells were obtained from Lonza (Walkersville, MD, USA) and grown 4 days in the presence of the receptor activator of nuclear factor kappa-B ligand (50 ng/ml) and GMCSF $(50 \mathrm{ng} / \mathrm{ml})$ followed by addition of spebrutinib or alendronate at indicated concentrations and incubated another 3 days. Plates were stained with tartrate-resistant acid phosphatase and osteoclasts were photographed and counted using Nikon NIS software.

\section{Clinical Study in RA Patients}

This study enrolled adult female patients only ( $\geq 18$ to 80 years of age); men were excluded from participating based on a preclinical toxicology finding of maturing spermatid degeneration in a 28-day study in mice. All patients had an RA diagnosis (based on the 2010 American College of Rheumatology [ACR]/European League Against Rheumatism [EULAR] Classification Criteria for Rheumatoid Arthritis) for $\geq 6$ months. Patients had to have active RA at the time of randomization, defined as at least six swollen joints and at least six tender joints, 
despite $\geq 3$ months of methotrexate therapy (7.5-25 mg/week, oral or parenteral) at a stable dose for $\geq 4$ weeks before randomization. In addition to background methotrexate therapy, treatment with non-steroidal anti-inflammatory drugs and pain medications, sulfasalazine and hydroxychloroquine or chloroquine, ondansetron and loperamide, lowdose corticosteroids (prednisone $\leq 10 \mathrm{mg}$ /day or equivalent), and antacids as needed ( $>2 \mathrm{~h}$ before or after dosing with study drug) was permitted.

\section{Study Design}

This phase $2 \mathrm{a}$, multicenter, double-blind, placebo-controlled, proof-of-concept study was conducted at 12 research sites in the United States from October 23, 2013, to February 11, 2016 (NCT01975610). The study was done in accordance with the International Conference on Harmonisation E6 requirements for Good Clinical Practice and in accordance with the ethical principles outlined in the Declaration of Helsinki. The study protocol, amendments, and informed consent form were approved by the institutional review board at each investigational site or by a central review board, and all enrolled patients provided written informed consent before starting the study. Schulman Associates IRB in Cincinnati, OH (IRB \#1 registration number 00000971) was the main ethics committee. The names of the independent ethics committee and/or institutional review board at each investigational site are listed in the Supplementary Material.

Patients were screened and then randomized (1:1) via an interactive voice response system to spebrutinib $375 \mathrm{mg} /$ day (administered in divided doses of $250 \mathrm{mg}$ in the morning and $125 \mathrm{mg}$ in the evening) or matching placebo capsules for 4 weeks in addition to their stable background methotrexate therapy (7.5-25 mg/week, oral or parenteral).

\section{Exclusion Criteria}

Patients were not eligible for enrollment if they had any other autoimmune disease or prior inflammatory joint disease other than RA; had used any biologic agent within 8 weeks or five half-lives of randomization; were receiving treatment with a disease-modifying anti-rheumatic drug (other than sulfasalazine, hydroxychloroquine or chloroquine, or methotrexate) or any other contraindicated medications or medical conditions; or had laboratory abnormalities or psychiatric illness that may affect participation in the study. Enrollment could be stopped after 48 patients were randomized for operational or administrative reasons. Patients experiencing nausea, diarrhea, vomiting, elevated liver function tests, or abnormal renal function during active treatment could have their dose of spebrutinib reduced to $125 \mathrm{mg}$, to be taken in the morning. One spebrutinibtreated patient had a dose reduction because of abnormal renal function parameters (i.e., Modification of Diet in Renal Disease estimated glomerular filtration rate $\geq 70 \mathrm{ml} / \mathrm{min} / 1.73 \mathrm{~m}^{2}$ and albumin/creatinine level between 61 and $300 \mathrm{mg} / \mathrm{g}$ ). At the end of the double-blind, placebo-controlled treatment period, patients continued into a 4-week, post-dose, observational follow-up period.

\section{Efficacy Assessments}

The primary endpoint was the proportion of patients who achieved $\geq 20 \%$ improvement in ACR response criteria (ACR20) at week 4 with spebrutinib versus placebo. Secondary efficacy endpoints included the proportions of patients who achieved $\mathrm{a} \geq 50 \%$ and $\geq 70 \%$ improvement in ACR response criteria (ACR50 and ACR70) at week 4 . A post hoc analysis compared ACR20 response rates at week 4 in patients with and without prior biologics.

\section{Safety Assessments}

At the time of study initiation, available toxicology study data for spebrutinib supported a 4-week proof-of-concept study and not a longer period. Secondary endpoints assessing the safety and tolerability of spebrutinib compared with placebo included collection of treatmentemergent adverse events (TEAEs), physical and 
ophthalmologic examinations, 12-lead electrocardiograms, and laboratory assessments.

\section{Subgroup Analyses}

Subgroup analyses assessed patient demographics and disease characteristics at baseline in ACR20 responders and non-responders. Additional post hoc analyses compared the biomarker changes from baseline to week 4 in responders versus non-responders and compared baseline biomarker levels between responders and non-responders.

\section{Pharmacodynamic Assessments}

Samples for pharmacodynamic and biomarker assessments were collected before the morning dose. The primary pharmacodynamic assessment was the percent BTK target site occupancy by spebrutinib, as previously described [7]. Additional assessments included the ratio of free:total BTK and changes in the concentration of serum carboxy-terminal collagen cross-linking telopeptide (CTX-I), a collagen type I fragment released by bone-resorbing osteoclasts. Circulating B-cell subsets examined by flow cytometry included total B cells, mature naive B cells, transitional B cells, and circulating classswitched and activated memory B cells. Circulating factors assessed by cytometric bead array included von Willebrand factor, eosinophil chemotactic protein-1, macrophage inflammatory protein-1 $\beta$ (MIP-1 $\beta$ ), haptoglobin, IL-18, matrix metalloproteinase-9, stem cell factor, brain-derived neurotrophic factor, IL-6, regulated on activation normal T cell (expressed and secreted), tissue inhibitor of metalloproteinase1, factor VII, hyaluronic acid, and ferritin. Chemokine ligand 13 (CXCL13) was measured by high-sensitivity Simoa assay (Myriad RulesBased Medicine, Austin, TX, USA).

\section{Statistical Analysis}

The target sample size of 80 patients (i.e., 40 per group) was based on the assumption that ACR20 response rates would be $60 \%$ for the spebrutinib group and $30 \%$ for the placebo group and would allow for approximately 80\% statistical power to detect a treatment difference in the ACR20 response rate (based on a Chisquare test with a two-sided significance level of $\alpha=0.1$ ). Study enrollment was prematurely halted due to slow recruitment.

Efficacy analyses were performed on the full analysis set, which included all randomized patients. The primary efficacy endpoint was evaluated using a Chi-square test with continuity correction and using non-responder imputation, where $P<0.1$ was considered statistically significant, which is equivalent to a one-sided test at 0.05 . A post hoc analysis was also performed for ACR20 at week 4 comparing prior biologics use (yes vs. no). The analyses of secondary efficacy endpoints of ACR50 and ACR70 response rates at week 4 were performed in a manner similar to the analysis of the primary endpoint. Post hoc biomarker analyses of patients achieving an ACR20, ACR50, or ACR70 response at week 4 were evaluated using descriptive statistics. Secondary safety endpoints were evaluated with descriptive statistics in the safety population (i.e., all patients who were randomized and received at least one dose of study medication).

Considering the low recruitment in this study, we were interested in exploring how many patients would have been required to power the study to detect a statistically significant between-group difference based on observed ACR20 response rates for each group. A post hoc analysis showed 80 patients would have achieved a $P$ value of 0.051 based on a twosided Chi-square test, assuming the observed $20 \%$ between-group effect size for the ACR20 response rate was maintained.

For pharmacodynamic analyses, the pharmacodynamic population included all patients with baseline data and at least one post-baseline sample collected for any biomarker. Descriptive statistics were performed using GraphPad Prism version 7.03 (GraphPad Software, Inc., La Jolla, CA, USA). $P$ values (two-tailed) were calculated based on comparisons of the active treatment versus placebo groups using a Wilcoxon signedrank test on the median change from baseline values. 


\section{RESULTS}

\section{Preclinical Pharmacology}

To explore spebrutinib pharmacology on immune responses, various primary human cellular models were tested using lymphoid and myeloid cells in vitro. Spebrutinib inhibited B-cell proliferation with an $\mathrm{IC}_{50}$ of $0.7 \mu \mathrm{M}$; reduced expression of activation markers CD86, CD40, CD54, and CD69; and inhibited IL-6 production (Table 1). B-cell differentiation to plasmablasts was inhibited, as was their ability to secrete IgG. T-cell proliferation was inhibited with an $\mathrm{IC}_{50}$ of $4.6 \mu \mathrm{M}$, which was 6.5 -fold less potent than inhibition of B-cell proliferation. T-cell interferon- $\gamma$ production, as well as degranulation of $\mathrm{T}$ cells and NK cells, was inhibited by spebrutinib in the $1-$ to $10-\mu \mathrm{M}$ range. In myeloid cells, spebrutinib reduced Fc $\gamma$ R-stimulated macrophage TNF- $\alpha$ production and Toll-like receptor 9-stimulated dendritic cell CD86 expression. Potent inhibition of FCeR-induced basophil degranulation $\left(\mathrm{IC}_{50}<1 \mu \mathrm{M}\right)$ and osteoclastogenesis were observed $(66 \%$ at $0.1 \mu \mathrm{M})$ (Table 1$)$. This pharmacologic effects pattern, including suppression of adaptive and innate immune responses, combined with inhibition of osteoclastogenesis and good in vivo efficacy in the collagen-induced arthritis model [7], led to testing spebrutinib in a phase 2 proof-of-concept clinical trial of patients with RA.

\section{Clinical Study in RA Patients}

Forty-seven patients were randomized (placebo: $N=23$; spebrutinib: $N=24$ ) and 44 (22 in each group) completed treatment during the study period. Three patients were discontinued for a protocol violation (placebo: $N=1$ ) and withdrawal of consent (spebrutinib: $N=2$ ).

Baseline patient demographics and disease characteristics were well balanced between treatment groups (Table 2). Mean age for patients was 54.8 years; most $(66.0 \%)$ patients were 40-65 years of age and the majority (78.7\%) were white. Mean body mass index of participants was $31.1 \mathrm{~kg} / \mathrm{m}^{2}$.

\section{ACR Responses}

The primary endpoint, ACR20 response at week 4 , was achieved by $41.7 \%(10 / 24)$ of spebrutinib-treated patients versus $21.7 \%(5 / 23)$ of placebo patients. Although the trend favored treatment with spebrutinib, the difference between spebrutinib and placebo (20\%) was not statistically significant $(P=0.2493) \quad$ (Fig. 1$)$. Some spebrutinib-treated patients achieved an ACR20 response as early as week 1, and responses continued through week 2 and week 4. For secondary efficacy endpoints, week 4 ACR50 response rates were $16.7 \%(4 / 24)$ with spebrutinib and $8.7 \%(2 / 23)$ with placebo, while week 4 ACR70 response rates were $8.3 \%(2 / 24)$ and $4.3 \%(1 / 23)$, respectively. Percent differences between spebrutinib and placebo regarding ACR50 response $(8.0 \%)$ and ACR70 response $(4.0 \%)$ were not statistically significant $(P=0.7029$ and $P=1.0000, \quad$ respectively) (Fig. 1).

In post hoc analyses comparing week 4 ACR20 response rates in patients with and without prior biologic therapy, the effect observed in spebrutinib-treated patients versus placebo patients was consistent with the primary efficacy results. Specifically, $60 \%(3 / 5)$ of spebrutinib-treated patients and 20\% (1/5) of placebo patients previously treated with biologics achieved an ACR20 response at week 4 .

\section{Subgroup Analyses Among ACR20 Responders}

Subgroup analyses of responder versus non-responder patients demonstrated that responders in both the placebo and spebrutinib treatment arms had a shorter duration of disease compared with non-responders. The mean duration of RA disease was 3.4 years among responders in both the placebo and spebrutinib treatment arms, compared with 7.6 years for non-responders in the placebo arm and 9.7 years for nonresponders in the spebrutinib treatment arm (Table 3). There was no difference in disease severity between responders and non-responders, as evidenced by the baseline 28-joint count Disease Activity Score, swollen and 
Table 1 Preclinical pharmacology of spebrutinib (CC-292)

\begin{tabular}{|c|c|c|}
\hline Enzyme or cell type & Assay & Spebrutinib ( $\mathrm{IC}_{50}$ or \% inhibition) \\
\hline BTK & Enzymatic activity & $<0.5 \mathrm{nM}$ \\
\hline $\mathrm{B}$ cell & PLC $\gamma 2$ phosphorylation (anti-IgM $+\mathrm{CpG}$ ) & $<0.1 \mu \mathrm{M}$ \\
\hline B cell & Proliferation (anti-IgM + CpG) & $0.7 \mu \mathrm{M}$ \\
\hline B cell & CD86, CD40, CD54, CD69 expression & $\sim 50 \% @ 1 \mu \mathrm{M}$ \\
\hline \multirow[t]{2}{*}{ B cell } & \multirow[t]{2}{*}{ IL-6 production } & $9 \% @ 3 \mu \mathrm{M}$ \\
\hline & & $85 \% @ 10 \mu \mathrm{M}$ \\
\hline B cell & Plasmablast differentiation & $87.5 \% @ 10 \mu \mathrm{M}$ \\
\hline B cell & IgG production & $52 \% @ 1 \mu \mathrm{M}$ \\
\hline $\mathrm{T}$ cell & TCR stimulation proliferation & $4.6 \mu \mathrm{M}$ \\
\hline \multirow[t]{3}{*}{$\mathrm{T}$ cell } & \multirow[t]{3}{*}{ Interferon- $\gamma$ production } & $0 \% @ 0.1 \mu \mathrm{M}$ \\
\hline & & $93 \% @ 1 \mu \mathrm{M}$ \\
\hline & & $99 \% @ 10 \mu \mathrm{M}$ \\
\hline $\mathrm{T}$ cell & Degranulation & $83 \% @ 10 \mu \mathrm{M}$ \\
\hline NK cells & Degranulation & $92 \% @ 10 \mu \mathrm{M}$ \\
\hline Macrophage & Fc $\gamma$ R-induced TNF- $\alpha$ production & $42 \% @ 1 \mu \mathrm{M}$ \\
\hline Myeloid dendritic cells & TLR9-induced CD86 expression & 94\%@0.1 $0 . \mathrm{M}$ \\
\hline Basophils & Fc\&R-induced degranulation & $<1 \mu \mathrm{M}$ \\
\hline Osteoclasts & Osteoclastogenesis & $66 \% @ 0.1 \mu \mathrm{M}$ \\
\hline
\end{tabular}

$B T K$ Bruton's tyrosine kinase, $F c \varepsilon R$ Fc-epsilon receptor, $F c \gamma R$ Fc-gamma receptor, $I L$ interleukin, $P L C \gamma 2$ phospholipase C $\gamma 2, T C R$ T-cell receptor, TLR9 Toll-like receptor 9, TNF- $\alpha$ tumor necrosis factor- $\alpha$

tender joint counts, or HAQ-DI at baseline (Table 3).

\section{Pharmacodynamics}

Median target occupancy by spebrutinib in the peripheral blood was $83 \%$ BTK detected in spebrutinib-treated patients beginning at week 1 , $86 \%$ at week 2 , and $88 \%$ at week 4 . Ratios of free:total BTK were significantly decreased with spebrutinib versus placebo during weeks 1,2 , and $4(P<0.01)$ (Fig. 2a). At week 4 , percent change from baseline in the ratio of free:total BTK was - 90.3\% with spebrutinib versus $-12.2 \%$ with placebo $(P=0.0405)$. Regarding the effect on specific B-lymphocyte subtypes, a significant increase in circulating total $\mathrm{CD} 19^{+} \mathrm{B}$ cells (Fig. 2b) and mature-naive $\mathrm{CD}^{2} 7^{-} \mathrm{CD}^{-} 8^{-} \mathrm{IgD}^{+}$B cells (Fig. 2c) was observed with spebrutinib versus placebo at week 4 $(P<0.05)$, whereas levels of transitional $\mathrm{CD}_{27}{ }^{-} \mathrm{CD} 8^{+} \quad \mathrm{B}$ cells (Fig. 2d) significantly decreased with spebrutinib versus placebo at the same time point $(P<0.05)$. With spebrutinib versus placebo, significantly greater percent increases from baseline in circulating total CD19 ${ }^{+}$B cells $(26.5$ vs. $2.6 \% ; P=0.0441)$ and mature-naïve $\mathrm{CD}^{2} 7^{-} \mathrm{CD} 38^{-} \mathrm{IgD}^{+} \mathrm{B}$ cells $(9.0$ vs. $-4.8 \% ; P=0.0112$ ) were observed at week 4 ; the percent change from baseline in $\mathrm{CD} 27^{-} \mathrm{CD}^{+} 8^{+} \mathrm{B}$ cells was $-50.9 \%$ with spebrutinib versus $21.2 \%$ with placebo $(P=0.0056)$. Examining effects on levels of 
Table 2 Baseline patient demographics and disease characteristics

\begin{tabular}{|c|c|c|}
\hline Characteristic & Placebo $(N=23)$ & Spebrutinib $375 \mathrm{mg} /$ day $(N=24)$ \\
\hline Age (years), mean (SD) & $54.6(13.2)$ & $55.0(14.6)$ \\
\hline \multicolumn{3}{|l|}{ Race, $n(\%)$} \\
\hline White & $17(73.9)$ & $20(83.3)$ \\
\hline African American & $6(26.1)$ & $4(16.7)$ \\
\hline Weight $(\mathrm{kg})$, mean $(\mathrm{SD})$ & $81.5(16.7)$ & $82.7(18.8)$ \\
\hline Body mass index $\left(\mathrm{kg} / \mathrm{m}^{2}\right)$, mean $(\mathrm{SD})$ & $30.8(6.3)$ & $31.3(7.5)$ \\
\hline Duration of RA (years), mean (SD) & $6.7(7.3)$ & $7.1(9.9)$ \\
\hline Swollen joint count $(0-66)$, mean $(S D)$ & $14.5(7.5)$ & $16.8(8.9)$ \\
\hline Tender joint count $(0-68)$, mean $(S D)$ & $26.3(14.8)$ & $26.5(13.8)$ \\
\hline hsCRP (mg/dl), mean (SD) & $6.6(8.1)$ & $5.5(5.5)$ \\
\hline DAS-28, mean (SD) & $5.2(0.9)$ & $5.4(1.0)$ \\
\hline HAQ-DI score, mean (SD) & $1.27(0.72)$ & $1.37(0.62)$ \\
\hline Erythrocyte sedimentation rate $(\mathrm{mm} / \mathrm{h})$, mean $(\mathrm{SD})$ & $32.1(18.2)$ & $29.2(14.6)$ \\
\hline Anti-CCP antibody positive, $n(\%)$ & $15(65.2)$ & $16(66.7)$ \\
\hline High rheumatoid factor, $n(\%)$ & $15(65.2)$ & $16(66.7)$ \\
\hline Methotrexate dose (mg/week), mean (SD) & $15.5(3.6)$ & $16.5(4.4)$ \\
\hline NSAID use, $n(\%)$ & $8(34.8)$ & $10(41.7)$ \\
\hline Oral corticosteroid use, $n(\%)$ & $4(17.4)$ & $5(20.8)$ \\
\hline Hydroxychloroquine or chloroquine, $n$ (\%) & $2(8.7)$ & $2(8.3)$ \\
\hline Prior use of biologic DMARDs, $n$ (\%) & $5(21.7)$ & $5(20.8)$ \\
\hline
\end{tabular}

Baseline use of NSAIDs was required to continue concomitantly, per protocol

$C C P$ cyclic citrullinated peptide, $D A S$-28 28-joint count Disease Activity Score, DMARDs disease-modifying anti-rheumatic drugs, hsCRP high-sensitivity C-reactive protein, NSAIDs non-steroidal anti-inflammatory drugs, $R A$ rheumatoid arthritis

circulating class switched and activated memory B cells, a trend toward reduced levels of these cell types was observed (data not shown).

Spebrutinib treatment significantly decreased median CTX-I levels versus placebo $(-14.7$ vs. $+8.5 \%)$ at week 4 , indicating decreased osteoclastogenesis (Fig. 3a). At week 4, CXCL13 significantly decreased in spebrutinib-treated patients, while it increased in patients treated with placebo (median - 26.73 vs. $5.36 \%$, respectively) (Fig. 3b). A significantly greater median percent decrease in MIP- $1 \beta$ was observed in spebrutinib-treated patients compared with placebo patients at week 4 ( -18.43 vs. $-2.12 \%$, respectively) (Fig. 3c). Haptoglobin increased with spebrutinib while placebo was unchanged (median +21.9 vs. - 8\%) (Fig. 3d). The von Willebrand factor increased in placebo patients over 4 weeks (median $+33.1 \%$ ), while spebrutinib-treated patients showed no significant change (median $+1.8 \%$ ) from baseline (data not shown). Nonsignificant treatment differences in serum factors were observed with $\alpha$-2-macroglobulin, $\beta$-2microglobulin, brain-derived neurotrophic factor, eosinophil chemotactic protein-1, 


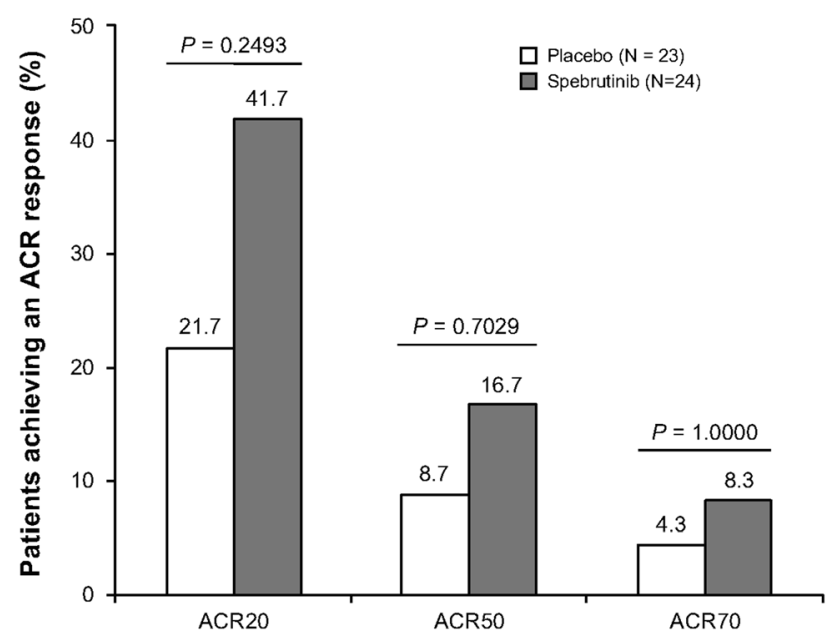

Fig. 1 Patients achieving ACR20, ACR50, and ACR70 responses at week 4. ACR American College of Rheumatology response criteria

C-reactive protein, complement C3, ferritin, IL6 , IL-8, regulated on activation normal $\mathrm{T}$ cell expressed and secreted, stem cell factor, soluble intracellular adhesion molecule-1, vascular epithelial growth factor, hyaluronic acid, and tissue inhibitor of metalloproteinase-1 (data not shown).

\section{Association Between Spebrutinib Pharmacodynamics and Clinical Response}

Post hoc analyses aimed at comparing pharmacodynamic changes between baseline and week 4 among spebrutinib clinical responders and non-responders revealed the following associations. Patients who achieved an ACR50 clinical response with spebrutinib treatment experienced a lower median percent increase in $\mathrm{CD}{ }^{+}$B cell levels from baseline to week 4 compared with ACR50 non-responders $(+15.4$ vs. $+42.9 \% ; P=0.06$ ) (Fig. 4 a). Similar trends were observed when comparing $\mathrm{CD} 19^{+} \mathrm{B}$ cell median percent change from baseline to week 4 in spebrutinib responders versus non-responders, as measured using ACR20 or ACR70 response criteria (Fig. 4a). There were no differences between spebrutinib responders and nonresponders for changes in mature-naïve $\mathrm{B}$ cells or transitional B cells (data not shown). For serum CXCL13, patients who achieved an ACR50 clinical response with spebrutinib experienced a greater median percent decrease from baseline to week 4 compared with ACR50 non-responders ( -47.2 vs. $-14.8 \% ; P=0.04$ ) (Fig. 4b). Similar trends were observed when comparing CXCL13 percent change from baseline to week 4 in spebrutinib responders versus non-responders, as measured using ACR20 or ACR70 response criteria (Fig. 4b). For serum MIP-1 $\beta$, patients who achieved an ACR20 clinical response with spebrutinib experienced a greater median percent decrease in MIP- $1 \beta$ level from baseline to week 4 compared with ACR20 non-responders ( -31.5 vs. $-8.7 \% ; P=0.10$ ) (Fig. 4c). Similar trends were observed when comparing median MIP-1 $\beta$ percent change from baseline to week 4 in spebrutinib responders versus non-responders, as measured using ACR50 or ACR70 response criteria (Fig. 4c).

\section{Biomarkers for Prediction of Clinical Response to Spebrutinib}

Post hoc analyses aimed at predicting spebrutinib clinical response revealed the following associations. Patients who achieved an ACR50 clinical response to spebrutinib treatment had a significantly higher median $\mathrm{CD} 19^{+} \mathrm{B}$ cell level in the blood at baseline compared with ACR50 non-responders $(18.8$ vs. $9.6 \% ; \quad P=0.027)$ (Fig. 5a). A similar relationship was observed when comparing median baseline $\mathrm{CD} 19^{+} \mathrm{B}$ cell 
Table 3 Baseline patient demographics and disease characteristics by ACR20 response status

\begin{tabular}{|c|c|c|c|c|}
\hline \multirow[t]{2}{*}{ Characteristic } & \multicolumn{2}{|l|}{ Placebo $(N=23)$} & \multicolumn{2}{|c|}{ Spebrutinib $375 \mathrm{mg} /$ day $(N=24)$} \\
\hline & $\begin{array}{l}\text { ACR20 non- } \\
\text { responders }(N=18)\end{array}$ & $\begin{array}{l}\text { ACR20 } \\
\text { responders } \\
(N=5)\end{array}$ & $\begin{array}{l}\text { ACR20 non- } \\
\text { responders }(N=14)\end{array}$ & $\begin{array}{l}\text { ACR20 } \\
\text { responders } \\
(N=10)\end{array}$ \\
\hline Age (years), mean (SD) & $57.2(12.4)$ & $45.0(12.5)$ & $55.5(17.4)$ & $54.3(10.3)$ \\
\hline \multicolumn{5}{|l|}{ Race, $n(\%)$} \\
\hline White & $13.0(72.2)$ & $4.0(80.0)$ & $12.0(85.7)$ & $8.0(80.0)$ \\
\hline African American & $5.0(27.8)$ & $1.0(20.0)$ & $2.0(14.3)$ & $2.0(20.0)$ \\
\hline Weight $(\mathrm{kg})$, mean $(\mathrm{SD})$ & $84.7(16.8)$ & $69.9(10.8)$ & $79.4(18.5)$ & $87.3(19.4)$ \\
\hline $\begin{array}{l}\text { Body mass index }\left(\mathrm{kg} / \mathrm{m}^{2}\right) \text {, mean } \\
(\mathrm{SD})\end{array}$ & $32.0(6.5)$ & $26.6(3.1)$ & $30.1(6.9)$ & $33.0(8.4)$ \\
\hline $\begin{array}{l}\text { Duration of RA (years), mean } \\
\text { (SD) }\end{array}$ & $7.6(8.0)$ & $3.4(1.7)$ & $9.7(12.1)$ & $3.4(3.8)$ \\
\hline $\begin{array}{l}\text { Swollen joint count }(0-66) \text {, } \\
\text { mean }(S D)\end{array}$ & $13.7(6.9)$ & $17.6(9.5)$ & $16.9(9.6)$ & $16.6(8.3)$ \\
\hline $\begin{array}{l}\text { Tender joint count }(0-68) \text {, } \\
\text { mean }(\mathrm{SD})\end{array}$ & $26.9(16.0)$ & $23.8(10.5)$ & $26.5(15.0)$ & $26.5(12.7)$ \\
\hline hsCRP (mg/dl), mean (SD) & $7.6(8.9)$ & $3.0(2.1)$ & $5.9(7.1)$ & $5.0(2.5)$ \\
\hline DAS-28, mean $(S D)$ & $5.3(0.9)$ & $4.9(0.9)$ & $5.3(1.2)$ & $5.5(0.8)$ \\
\hline HAQ-DI score, mean (SD) & $1.2(0.7)$ & $1.7(0.5)$ & $1.3(0.7)$ & $1.5(0.6)$ \\
\hline $\begin{array}{l}\text { Erythrocyte sedimentation rate } \\
\qquad(\mathrm{mm} / \mathrm{h}), \text { mean }(\mathrm{SD})\end{array}$ & $29.0(11.8)$ & $43.2(32.2)$ & $23.4(11.6)$ & $37.3(14.9)$ \\
\hline $\begin{array}{l}\text { Anti-CCP antibody positive, } \\
n(\%)\end{array}$ & $10.0(55.6)$ & $5.0(100.0)$ & $9.0(64.3)$ & $7.0(70.0)$ \\
\hline High rheumatoid factor, $n(\%)$ & $10.0(55.6)$ & $5.0(100.0)$ & $11.0(78.6)$ & $5.0(50.0)$ \\
\hline $\begin{array}{l}\text { Methotrexate dose (mg/week), } \\
\text { mean }(\mathrm{SD})\end{array}$ & $15.1(3.03)$ & $17.0(5.42)$ & $15.9(3.62)$ & $17.3(5.33)$ \\
\hline NSAID use, $n(\%)$ & $6.0(33.3)$ & $2.0(40.0)$ & $6.0(42.9)$ & $4.0(40.0)$ \\
\hline Oral corticosteroid use, $n(\%)$ & $2.0(11.1)$ & $2.0(40.0)$ & $2.0(14.3)$ & $3.0(30.0)$ \\
\hline $\begin{array}{l}\text { Hydroxychloroquine or } \\
\text { chloroquine, } n(\%)\end{array}$ & $1.0(5.6)$ & $1.0(20.0)$ & $2.0(14.3)$ & $0.0(0.00)$ \\
\hline $\begin{array}{l}\text { Prior use of biologic DMARDs, } \\
n(\%)\end{array}$ & $4.0(22.2)$ & $1.0(20.0)$ & $2.0(14.3)$ & $3.0(30.0)$ \\
\hline
\end{tabular}

$C C P$ cyclic citrullinated peptide, $D A S$-28 28-joint count Disease Activity Score, DMARDs disease-modifying anti-rheumatic drugs, $h s C R P$ high-sensitivity $\mathrm{C}$-reactive protein, NSAID non-steroidal anti-inflammatory drug, $R A$ rheumatoid arthritis 

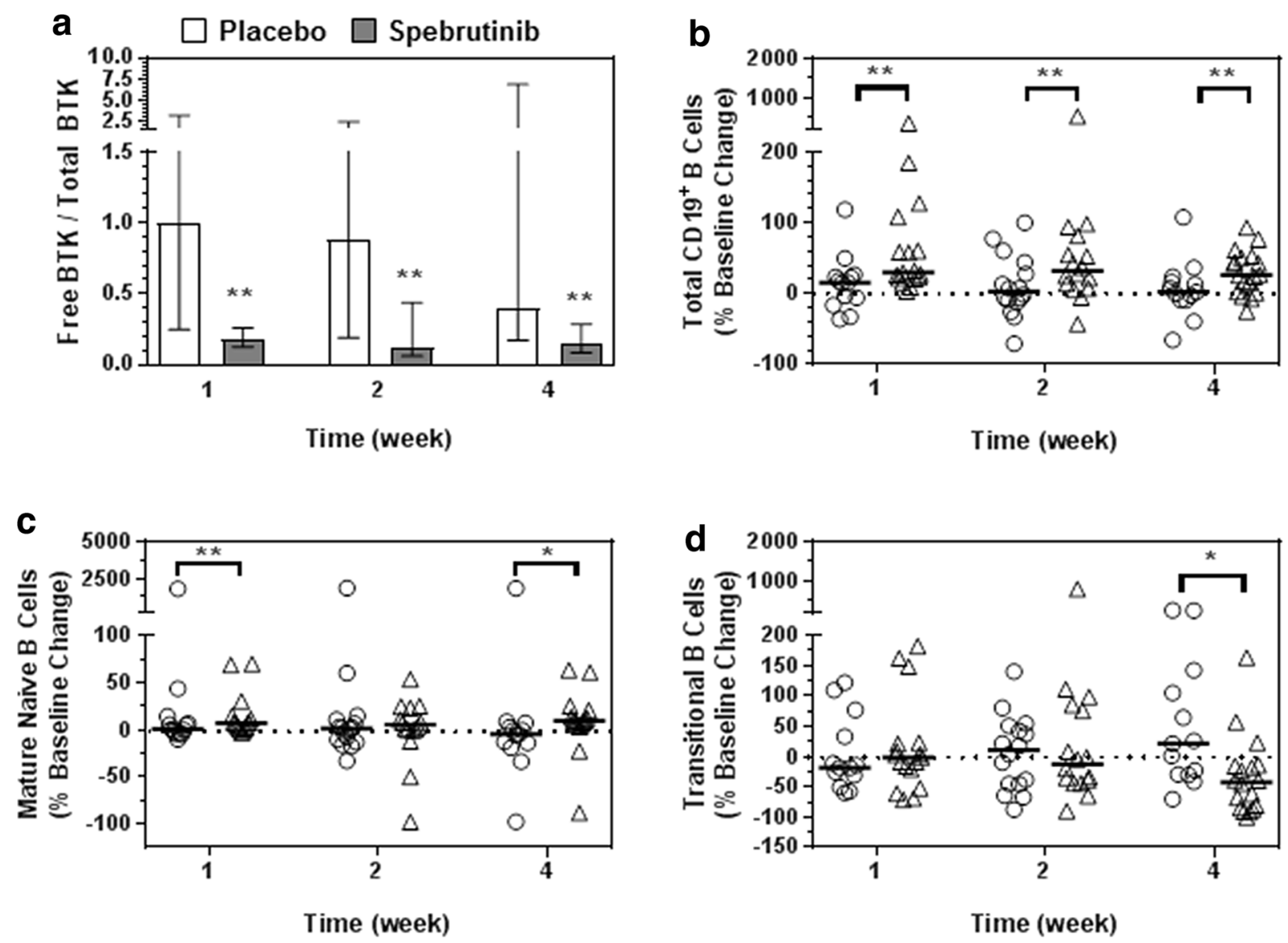

Fig. 2 Free BTK to total BTK in PBMC and spebrutinib's effects on B-cell subsets. a Fraction of free BTK to total BTK in PBMC and $\mathbf{b}-\mathbf{d}$ effects of spebrutinib on B-cell subsets in circulation. The binding of spebrutinib to BTK in PBMC is shown in a as the ratio of free (unbound) BTK to total BTK. Flow cytometry analysis of whole blood from patients at the indicated times posttreatment are shown as $\mathbf{b}$ percent change from baseline for

levels in spebrutinib ACR70 responders versus non-responders $(20.8$ vs. $11.0 \% ; \quad P=0.048)$ (Fig. 5a). The median baseline CTX-I serum level was significantly lower among spebrutinib ACR50 responders compared with ACR50 nonresponders $(0.39$ vs. $0.49 \mu \mathrm{g} / \mathrm{l} ; \quad P=0.032)$ (Fig. 5b). A similar trend was observed when comparing spebrutinib ACR20 or ACR70 responders with non-responders: the spebrutinib responders had a lower median CTX-I serum level at baseline than the non-responders (Fig. 5b). There were no differences in median

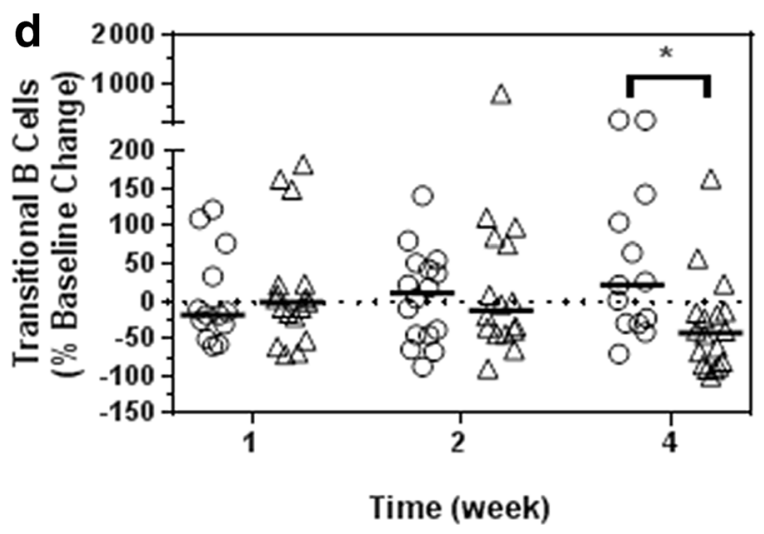

$\mathrm{CD} 19^{+}$total $\mathrm{B}$ cells, c $\mathrm{CD} 19^{+} \mathrm{CD} 27^{-} \mathrm{CD} 38^{-} \mathrm{IgD}^{+}$ mature naive $\mathrm{B}$ cells, and $\mathbf{d ~} \mathrm{CD} 19^{+} \mathrm{CD} 27^{-} \mathrm{CD} 38^{+}$transitional B cells at weeks 1, 2, and 4. Data are represented as median values $\pm 95 \%$ confidence interval of placebo (open circles) and spebrutinib treatment (open triangles). ${ }^{*} P<0.05 ; \quad{ }^{* *} P<0.01$ versus collection date-matched placebo. BTK Bruton's tyrosine kinase, PBMC peripheral blood mononuclear cells

baseline serum CXCL13 or MIP-1 $\beta$ levels between spebrutinib responders and non-responders (data not shown).

\section{Safety}

Spebrutinib was well tolerated over the 4-week treatment phase. Most TEAEs were mild or moderate in severity; one severe TEAE (stomatitis) was reported with spebrutinib. The most frequently reported events $(\geq 5 \%$ in either treatment group) were nausea, back pain, 

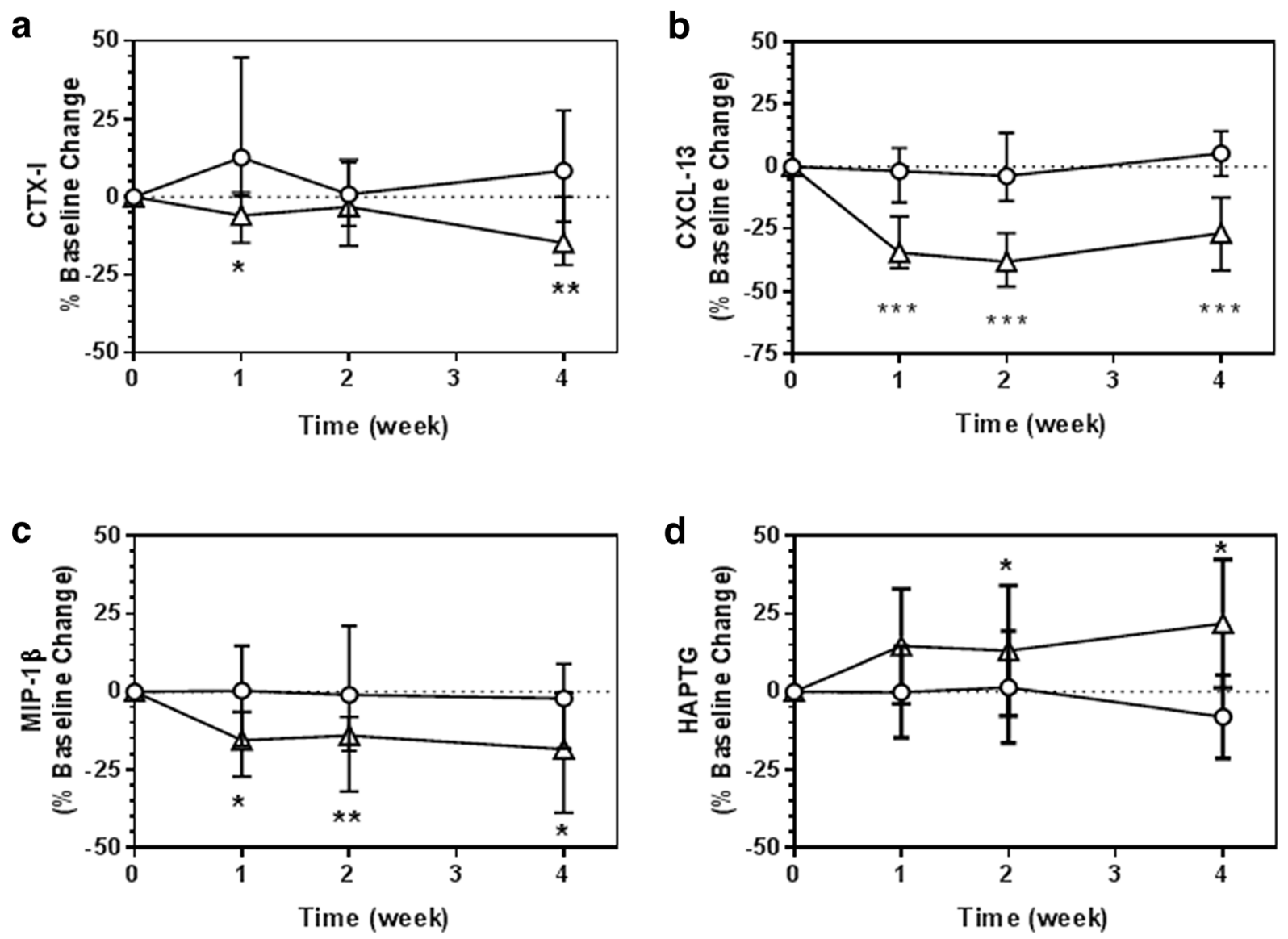

Fig. 3 Changes in CTX-I expression and inflammationassociated proteins over time after administration of spebrutinib. Plasma levels from subjects at the indicated times post-treatment are shown as percent change from baseline for a CTX-I, b CXCL13, c MIP-1 $\beta$, and d haptoglobin at weeks 1, 2, and 4. Data are represented

as the median $\pm 95 \%$ confidence interval of placebo (open circles) and spebrutinib treatment (open triangles). ${ }^{*} P<0.05 ;{ }^{* *} P<0.01 ;{ }^{* * *} P<0.001$ versus collection date-matched placebo. CTX-I carboxy-terminal collagen cross-linking telopeptide, CXCL13 chemokine ligand 13, $M I P-1 \beta$ macrophage inflammatory protein- $1 \beta$

diarrhea, cough, and migraine (Table 4); no patients were discontinued from spebrutinib because of TEAEs, and no serious TEAEs were reported during the study. No treatment-related trends were observed in hematology and serum chemistry results; few patients had markedly abnormal hematology values (placebo: $N=4$; spebrutinib: $N=3$ ).

Blood pressure, vital signs, electrocardiogram, and ophthalmologic findings were generally unremarkable with no treatment-related trends. TEAEs associated with electrocardiogram findings were reported in two spebrutinib-treated patients; however, neither event was

suspected to be related to treatment. TEAEs associated with ophthalmologic findings were reported in one spebrutinib-treated patient and one placebo patient; neither event was suspected to be related to treatment.

\section{DISCUSSION}

Using primary human immune cells, the covalent BTK inhibitor spebrutinib inhibited cellular responses associated with BTK signaling, including BCR, Fc $\gamma \mathrm{R}, \mathrm{Fc \varepsilon R}$, and Toll-like receptor 9 pathways. These effects included 

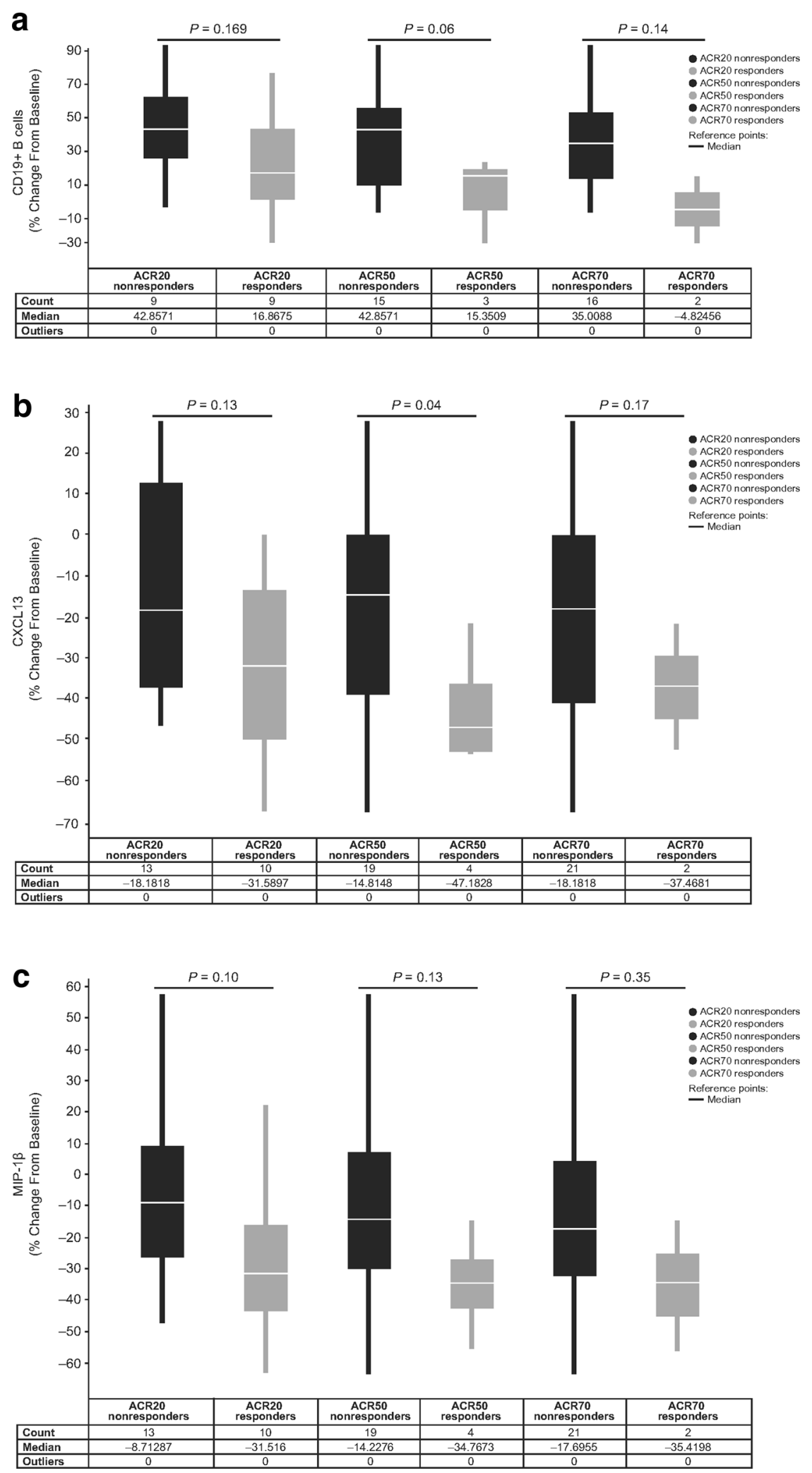
4Fig. 4 Association between clinical response to spebrutinib and changes in biomarkers. Change in a CD19 ${ }^{+} \mathrm{B}$ cells, b CXCL13, and c MIP-1 $\beta$ in peripheral blood of spebrutinib-treated patients from baseline to week 4, by ACR20, ACR50, and ACR70 response status. Data are represented as the median, minimum, maximum, and interquartile range

inhibition of B-cell proliferation and activation marker expression as well as Fc receptor-mediated cytokine production, degranulation, and osteoclastogenesis. These processes collectively contribute to antibody production, FcR binding, inflammation, and bone erosions characteristic of RA.

In this study comparing efficacy, safety, and pharmacodynamic properties of spebrutinib versus placebo in 47 patients with RA, $41.7 \%$ of spebrutinib-treated patients achieved an ACR20 response at week 4 versus $21.7 \%$ of placebo patients, representing a $20 \%$ difference in ACR20 responses between treatment groups. The magnitude of response observed with spebrutinib is similar to that seen with other agents used to treat RA [10-12]. However, the ACR20 response rate at week 4 (primary endpoint) was not significantly greater for spebrutinib versus placebo, and no advantage was detected based on any other clinical efficacy endpoint examined at week 4 .

Because of the small number of patients and short study duration, firm conclusions cannot be drawn regarding spebrutinib's potential clinical efficacy in treatment of patients with active RA. Nevertheless, clear and consistent trends toward greater therapeutic response with spebrutinib versus placebo were observed (e.g., ACR response rates were twofold greater with spebrutinib vs. placebo) but failed to reach statistical significance, likely due to statistical under-powering because of under-enrollment.

Unlike the clinical findings, spebrutinib treatment led to statistically significant changes versus placebo across several biomarkers of antiinflammatory activity, confirming its mechanism of action and potential therapeutic biologic effects in RA. With spebrutinib treatment, levels of free BTK were $<17 \%$ (weeks $1-4$ ) and were associated with an increase in total CD19 ${ }^{+}$
$B$ cells and mature-naïve $B$ cells and a reduction in the percentage of $\mathrm{CD} 27^{-} \mathrm{CD} 38^{+}$transitional $\mathrm{B}$ cells (precursors to antibody-secreting plasmablasts). This pattern of effects may represent a blockade in B-cell transition to the plasmablast stage. Spebrutinib treatment was also associated with a significant decrease in serum CTX-I (marker for osteoclast activity) and chemokines CXCL13 and MIP-1 $\beta$ (proteins involved in B-cell activation and trafficking). Clinical response to spebrutinib was associated with a lower increase in total $\mathrm{CD} 19^{+} \mathrm{B}$ cells in the blood and with a greater decrease in CXCL13 and MIP-1 $\beta$ levels in the serum. This association between the biomarker changes and clinical response to spebrutinib illustrates that these pharmacodynamic effects of BTK inhibition are clinically relevant. Furthermore, we found two baseline biomarkers that were associated with better clinical response to spebrutinib: Higher baseline levels of total CD $19^{+}$B cells in the blood and lower baseline levels of serum CTX-I were associated with significantly better ACR50 clinical response to spebrutinib (Fig. 5a, b). These findings suggest that aberrantly high B-cell function in RA disease and lower osteoclast activity may be predictors of superior clinical response to a BTK inhibitor. However, the sensitivity and specificity of such predictive biomarkers would require prospective testing in a randomized clinical trial before such a claim could be reliably made.

These biomarker changes are consistent with the known pharmacology of BTK inhibition and may represent clinically important changes in RA pathobiology. The BTK inhibitor ibrutinib, which is approved for treatment of the B-cell malignancies chronic lymphocytic leukemia, mantle cell lymphoma, and Waldenstrom macroglobulinemia, has been shown to reduce $\mathrm{CD}^{+}{ }^{+} \mathrm{B}$ cells in patients with mantle cell lymphoma [13]. Osteoclasts are mediators of bone damage in the joints of patients with RA, other forms of arthritis and osteoporosis. In preclinical studies, spebrutinib was shown to inhibit osteoclast activity, as measured by reduced pit formation in vitro, and reduce plasma CTX protein levels in an in vivo mouse model of multiple myeloma [8]. CXCL13 is an important mediator of lymphocyte homing to 

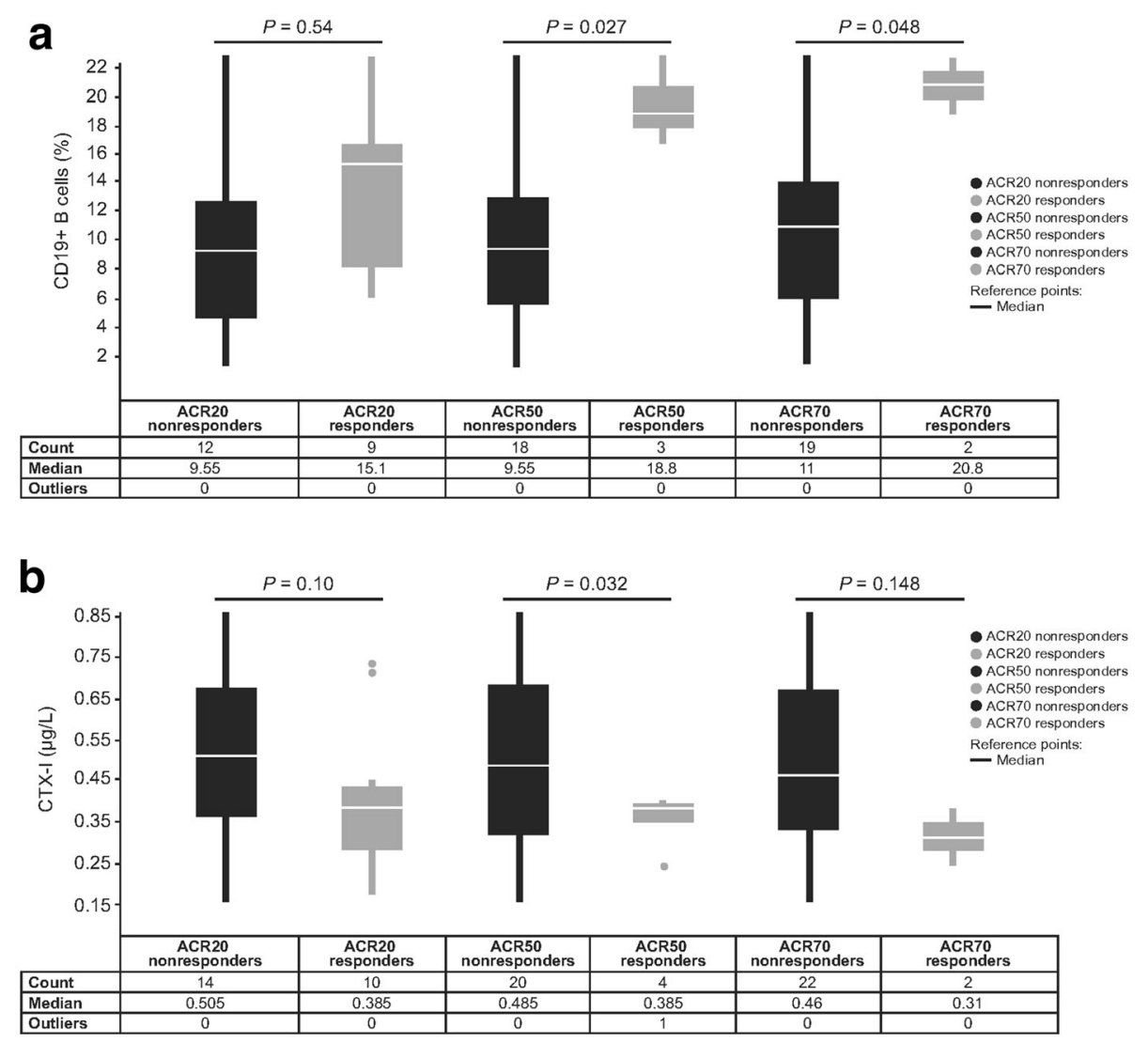

Fig. 5 Association between clinical response to spebrutinib and baseline biomarkers. Baseline levels of a $\mathrm{CD} 19^{+} \mathrm{B}$ cells and b CTX-I in peripheral blood of spebrutinib- treated patients by ACR20, ACR50, and ACR70 response status. Data are represented as the median, minimum, maximum, and interquartile range

Table 4 Adverse events reported during the 4-week placebo-controlled study period

\begin{tabular}{lcc}
\hline Patients & Placebo $(\boldsymbol{N}=\mathbf{2 3})$ & Spebrutinib 375 mg/day $(\boldsymbol{N}=\mathbf{2 4})$ \\
\hline Adverse events, $n(\%)$ & $11(47.8)$ & $14(58.3)$ \\
$\geq 1$ adverse event & $0(0.0)$ & $0(0.0)$ \\
$\geq 1$ serious adverse event & $0(0.0)$ & $1(4.2)$ \\
$\geq 1$ severe adverse event & $0(0.0)$ & $0(0.0)$ \\
Adverse event leading to drug withdrawal & $2(8.7)$ & $5(20.8)$ \\
Adverse events in any treatment group $(\geq 5 \%$ of patients),n(\%) & $2(8.3)$ \\
Nausea & $1(4.3)$ & $2(8.3)$ \\
Back pain & $1(4.3)$ & $2(8.3)$ \\
Diarrhea & $0(0.0)$ & $2(8.3)$ \\
Cough & $0(0.0)$ & \\
Migraine & & \\
\hline
\end{tabular}


the lymph node, which occurs in a BTK-dependent manner [4]. Ibrutinib has been shown to directly inhibit CXCL13 production by macrophages in vitro [14]. Ibrutinib was shown to reduce blood CXCL13 protein levels in patients with mantle cell lymphoma [11] and Waldenstrom macroglobulinemia; high CXCL13 levels at baseline were associated with major clinical response in patients with Waldenstrom macroglobulinemia [15]. CXCL13 is highly relevant in the pathogenesis of RA, as high CXCL13 expression levels in the RA synovium have been associated with a lymphoid synovial phenotype; CXCL13 is more frequently observed in patients with RA who express anti-citrullinated protein antibodies and is a marker of more severe disease [16]. Furthermore, high CXCL13 serum levels have been reproducibly associated with poor clinical response to anti-TNF biologic in patients with RA $[17,18]$. Thus, the ability of a BTK inhibitor to reduce $\mathrm{CD}^{+} 8^{+} \mathrm{B}$ cells, osteoclast-mediated bone damage, and CXCL13-mediated lymphocytic inflammation would be potentially meaningful pathobiologic changes in patients with RA.

During the review of this report, it was reported that the BTK inhibitor fenebrutinib significantly improved ACR50 clinical response rates in RA patients with an inadequate response to methotrexate or TNF inhibitors (Cohen S, et al. EULAR 2019 [abstract OP0025]; 12 June 2019; Madrid, Spain). The fenebrutinib study enrolled 480 patients, and the treatment duration was 12 weeks. By comparison, the current spebrutinib RA study was much smaller, enrolling only 47 patients, with a treatment duration of only 4 weeks. Nonetheless, both the fenebrutinib study and the spebrutinib trials showed similar pharmacodynamic effects by these two BTK inhibitors. Fenbrutinib, which is a reversible BTK inhibitor, significantly decreased CXCL13 and MIP-1 $\beta$ (CCL4) (Morimoto A, et al. EULAR 2019 [abstract FRI0129]; 14 June 2019; Madrid, Spain). Spebrutinib, which is an irreversible BTK inhibitor, likewise reduced CXCL13 and MIP-1 $\beta$ (CCL4) (Fig. 3b, c). Therefore, regardless of whether the BTK inhibitor binds in a reversible or irreversible manner, the pharmacodynamic effects on downstream B-cell and myeloid chemokines appear to be the same.

Spebrutinib was well tolerated, as most TEAEs were mild or moderate in severity and no patient experienced a TEAE resulting in study discontinuation or dose reduction. Nausea was the most common TEAE reported; no other individual events were experienced by more than two patients in either group. Overall, there were no remarkable findings or changes in laboratory evaluations, vital sign measurements, electrocardiogram readings, or ophthalmologic examinations.

This study had several limitations. The study duration was 4 weeks and low enrollment under-powered the study; therefore, a therapeutic benefit of spebrutinib versus placebo could not be detected. Another limitation was the short-term treatment period of 4 weeks. Finally, the spebrutinib dose in this study was chosen based on a small phase 1 study in healthy volunteers [7]. Higher spebrutinib doses (up to $1000 \mathrm{mg}$ /day) were administered safely in a phase 1 study in patients with relapsed/refractory chronic lymphocytic leukemia [19]; therefore, the current study might have been more informative if a higher range of spebrutinib doses had been used.

\section{CONCLUSIONS}

In summary, although a clear conclusion on the clinical benefit of spebrutinib cannot be made, significant pharmacodynamic findings and numerical trends in efficacy observed in spebrutinib-treated patients suggest covalent BTK inhibition may have clinical potential for the treatment of RA.

\section{ACKNOWLEDGEMENTS}

The authors thank the patients who participated in this study and multiple study sites and study investigators.

Funding. This study and the Rapid Service Fee were funded by Celgene Corporation. 
Editorial Assistance. The authors received editorial support in the preparation of this report from Kristin Carlin, RPh, MBA, of Peloton Advantage, LLC, an OPEN Health company, Parsippany, NJ, USA, sponsored by Celgene Corporation, Summit, NJ, USA. The authors, however, directed and are fully responsible for all content and editorial decisions for this report.

Authorship. All named authors meet the International Committee of Medical Journal Editors (ICMJE) criteria for authorship for this article, take responsibility for the integrity of the work as a whole, and have given their approval for this version to be published.

Authorship Contributions. All authors were involved in the drafting and critical review of the manuscript and approved the final version for submission. PHS, AJK, JM, SK, DS, LL, AA, JK, MA, LC, EMH, DRH, and GER were involved with the conception or design of the work, the development of the statistical analysis plan, and the acquisition of clinical data and participated in the clinical study from which data are reported in the manuscript. All authors agree to be accountable for all aspects of the work and attest to the accuracy and integrity of the work.

Disclosures. Peter H. Schafer is an employee of and has stocks or stock options in Celgene Corporation. Jianglin $\mathrm{Ma}$ is an employee of and has stocks or stock options in Celgene Corporation. Shimon Korish is an employee of and has stocks or stock options in Celgene Corporation. Donna Sutherland is an employee of and has stocks or stock options in Celgene Corporation. $\mathrm{Li} \mathrm{Li}$ is an employee of and has stocks or stock options in Celgene Corporation. Jolanta Kosek is an employee of and has stocks or stock options in Celgene Corporation. Mary Adams is an employee of and has stocks or stock options in Celgene Corporation. Lori Capone is an employee of and has stocks or stock options in Celgene Corporation. Eun Mi Hur is an employee of and has stocks or stock options in Celgene Corporation. Garth E. Ringheim is an employee of and has stocks or stock options in Celgene Corporation. Alan J. Kivitz has received grant/research support and served as a consultant and speaker for Celgene Corporation. Ada Azaryan was employed by Celgene Corporation at the time of study conduct and is now employed by Genmab USA, Inc. Douglas R. Hough was an employee of Celgene Corporation at the time of study conduct and is now retired.

Compliance with Ethics Guidelines. The study was done in accordance with the International Conference on Harmonisation E6 requirements for Good Clinical Practice and in accordance with the ethical principles outlined in the Declaration of Helsinki. The study protocol, amendments, and informed consent form were approved by the institutional review board at each investigational site or by a central review board, and all enrolled patients provided written informed consent before starting the study. Schulman Associates IRB in Cincinnati, OH (IRB \#1 registration number 00000971) was the main ethics committee. The names of the independent ethics committee and/or institutional review board at each investigational site are listed in the Supplementary Material.

Data Availability. Celgene is committed to responsible and transparent sharing of clinical trial data with patients, healthcare practitioners, and independent researchers for the purpose of improving scientific and medical knowledge as well as fostering innovative treatment approaches. For more information, please visit: https://www.celgene.com/researchdevelopment/clinical-trials/clinical-trials-datasharing/.

Open Access. This article is distributed under the terms of the Creative Commons Attribution-NonCommercial 4.0 International License (http://creativecommons.org/licenses/ by-nc/4.0/), which permits any noncommercial use, distribution, and reproduction in any medium, provided you give appropriate credit to the original author(s) and the source, provide a link to the Creative Commons license, and indicate if changes were made. 


\section{REFERENCES}

1. Chang BY, Huang MM, Francesco M, Chen J, Sokolove J, Magadala P, et al. The Bruton tyrosine kinase inhibitor PCI-32765 ameliorates autoimmune arthritis by inhibition of multiple effector cells. Arthritis Res Ther. 2011;13(4):R115.

2. Niiro H, Clark EA. Regulation of B-cell fate by antigen-receptor signals. Nat Rev Immunol. 2002;2(12):945-56.

3. Khan WN. Regulation of B lymphocyte development and activation by Bruton's tyrosine kinase. Immunol Res. 2001;23(2-3):147-56.

4. de Gorter DJ, Beuling EA, Kersseboom R, Middendorp S, van Gils JM, Hendriks RW, et al. Bruton's tyrosine kinase and phospholipase $\mathrm{C} \gamma 2$ mediate chemokine-controlled B cell migration and homing. Immunity. 2007;26(1):93-104.

5. de Rooij MF, Kuil A, Geest CR, Eldering E, Chang BY, Buggy JJ, et al. The clinically active BTK inhibitor PCI-32765 targets B-cell receptor- and chemokine-controlled adhesion and migration in chronic lymphocytic leukemia. Blood. 2012;119(11):2590-4.

6. Kivitz A, Gupta R, Valenzuela G, Smith E, Rehman Q, El-Kadi $\mathrm{H}$, et al. A phase 2a, 4-week double-blind, proof-of-concept efficacy and safety study of CC292 versus placebo as co-therapy with methotrexate in active rheumatoid arthritis [poster 1587]. Presented at: the Annual Meeting of the American College of Rheumatology; November 12-16, 2016; Washington, DC.

7. Evans EK, Tester R, Aslanian S, Karp R, Sheets M, Labenski MT, et al. Inhibition of Btk with CC-292 provides early pharmacodynamic assessment of activity in mice and humans. J Pharmacol Exp Ther. 2013;346(2):219-28.

8. Eda H, Santo L, Cirstea DD, Yee AJ, Scullen TA, Nemani N, et al. A novel Bruton's tyrosine kinase inhibitor CC-292 in combination with the proteasome inhibitor carfilzomib impacts the bone microenvironment in a multiple myeloma model with resultant antimyeloma activity. Leukemia. 2014;28(9):1892-901.

9. Nakayama Y, Kosek J, Capone L, Hur EM, Schafer $\mathrm{PH}$, Ringheim GE. Aiolos overexpression in systemic lupus erythematosus B cell subtypes and BAFF-induced memory B cell differentiation are reduced by CC-220 modulation of cereblon activity. J Immunol. 2017;199(7):2388-407.

10. Weinblatt ME, Fleischmann R, Huizinga TW, Emery P, Pope J, Massarotti EM, et al. Efficacy and safety of certolizumab pegol in a broad population of patients with active rheumatoid arthritis: results from the REALISTIC phase IIIb study. Rheumatology (Oxford). 2012;51(12):2204-14.

11. Hobbs K, Deodhar A, Wang B, Bitman B, Nussbaum J, Chung J, et al. Randomized, double-blind, placebo-controlled study to evaluate the efficacy and safety of etanercept in patients with moderately active rheumatoid arthritis despite DMARD therapy. SpringerPlus. 2015;4:113.

12. van de Putte LB, Atkins C, Malaise M, Sany J, Russell AS, van Riel PL, et al. Efficacy and safety of adalimumab as monotherapy in patients with rheumatoid arthritis for whom previous disease-modifying antirheumatic drug treatment has failed. Ann Rheum Dis. 2004;63(5):508-16.

13. Chang BY, Francesco M, De Rooij MF, Magadala P, Steggerda SM, Huang MM, et al. Egress of CD19(+)CD5(+) cells into peripheral blood following treatment with the Bruton tyrosine kinase inhibitor ibrutinib in mantle cell lymphoma patients. Blood. 2013;122(14):2412-24.

14. Ping L, Ding N, Shi Y, Feng L, Li J, Liu Y, et al. The Bruton's tyrosine kinase inhibitor ibrutinib exerts immunomodulatory effects through regulation of tumor-infiltrating macrophages. Oncotarget. 2017;8(24):39218-29.

15. Vos JM, Tsakmaklis N, Patterson CJ, Meid K, Castillo JJ, Brodsky P, et al. CXCL13 levels are elevated in patients with Waldenstrom's macroglobulinemia, and are predictive of major response to ibrutinib. Haematologica. 2017;102(11):e452-5.

16. Bugatti S, Manzo A, Vitolo B, Benaglio F, Binda E, Scarabelli M, et al. High expression levels of the B cell chemoattractant CXCL13 in rheumatoid synovium are a marker of severe disease. Rheumatology (Oxford). 2014;53(10):1886-95.

17. Dennis G Jr, Holweg CT, Kummerfeld SK, Choy DF, Setiadi AF, Hackney JA, et al. Synovial phenotypes in rheumatoid arthritis correlate with response to biologic therapeutics. Arthritis Res Ther. 2014;16(2):R90.

18. Folkersen L, Brynedal B, Diaz-Gallo LM, Ramsköld $\mathrm{D}$, Shchetynsky $\mathrm{K}$, Westerlind $\mathrm{H}$, et al. Integration of known DNA, RNA and protein biomarkers provides prediction of anti-TNF response in rheumatoid arthritis: results from the COMBINE study. Mol Med. 2016;22:322-8.

19. Brown JR, Harb WA, Hill BT, Gabrilove J, Sharman JP, Schreeder MT, et al. Phase I study of single-agent CC-292, a highly selective Bruton's tyrosine kinase inhibitor, in relapsed/refractory chronic lymphocytic leukemia. Haematologica. 2016;101(7):e295-8. 